\title{
Lightweighting Impacts on Fuel Economy, Cost, and Component Losses
}

\author{
Aaron David Brooker \\ National Renewable Energy Laboratory \\ Jacob Ward \\ Department Of Energy \\ Lijuan Wang \\ National Renewable Energy Laboratory
}

doi: $\underline{10.4271 / 2013-01-0381}$

\begin{abstract}
In 2011, the United States imported almost half of its petroleum. Lightweighting vehicles reduces that dependency directly by decreasing the engine, braking and rolling resistance losses, and indirectly by enabling a smaller, more efficiently operating engine to provide the same performance.

The Future Automotive Systems Technology Simulator (FASTSim) tool was used to quantify these impacts. FASTSim is the U.S. Department of Energy's (DOE's) highlevel vehicle powertrain model developed at the National Renewable Energy Laboratory. It steps through a time versus speed drive cycle to estimate the powertrain forces required to meet the cycle. It simulates the major vehicle powertrain components and their losses. It includes a cost model based on component sizing and fuel prices.
\end{abstract}

FASTSim simulated different levels of lightweighting for four different powertrains. The four powertrains included a conventional gasoline engine vehicle, a hybrid electric vehicle (HEV), a plug-in hybrid electric vehicle (PHEV), and a battery electric vehicle (EV).

Weight reductions impacted the conventional vehicle efficiency more than the HEV, PHEV and EV. Although lightweighting impacted advanced vehicle efficiency less, it reduced component cost and overall costs more. Under the assumed current battery costs, however, the PHEV and EV were still more expensive than the conventional vehicle and HEV. Assuming the DOE's battery cost target of $\$ 125 / \mathrm{kWh}$ and improved battery life, however, the PHEV and EV attained similar cost and lightweighting benefits. Generally, lightweighting was cost effective when it cost less than $\$ 6 / \mathrm{kg}$ of mass eliminated.

\section{INTRODUCTION}

U.S. transportation is largely dependent on foreign petroleum. In 2011, petroleum supplied $93 \%$ of transportation energy [1] as seen in Figure 1, with almost half coming from foreign nations [ㄹ] .

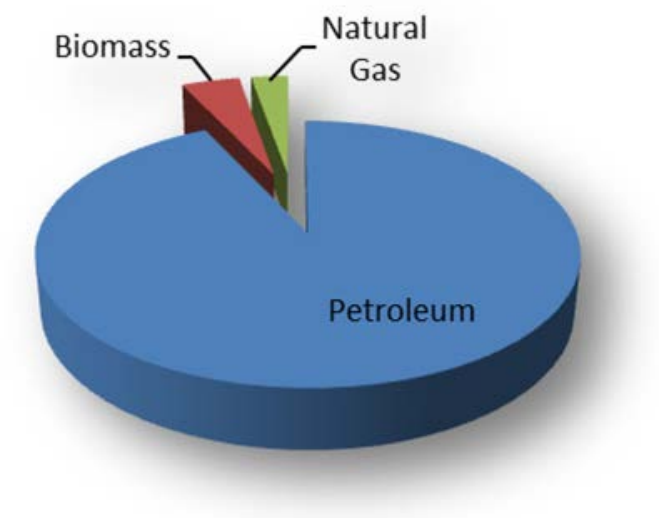

Figure 1. Transportation sector energy consumption

Lightweighting can reduce U.S. petroleum dependency in several ways. One, it reduces the rolling resistance of tires, which is proportional to the weight of the vehicle. Two, it reduces the amount of energy required to accelerate a vehicle or climb a hill, which ultimately reduces the amount of 
energy lost to friction brakes. Three, lightweighting reduces the engine size needed to meet the same acceleration and grade performance, and smaller engines tend to run at higher average efficiencies. Four, it can improve the attractiveness, and thus sales, of vehicles that do not use petroleum. For example, lightweighting plug-in hybrid electric vehicles (PHEVs) and electric vehicles (EVs) reduces the amount of battery energy needed to achieve the same range, which reduces cost and improves sales.

Several lightweighting options include:

- High strength steel

- Aluminum

- Magnesium

- Polymer composites

These options have different mass reductions and cost impacts. This paper looks at the mass, petroleum, and cost effectiveness at different lightweighting cost and mass levels.

\section{APPROACH}

Vehicle powertrains with comparable attributes were used to assess the impacts of lightweighting. This study assumed a base vehicle similar to the 2012 Nissan Leaf. The powertrain was modified to a comparable conventional vehicle, hybrid electric vehicle (HEV), and PHEV powertrain. The baseline glider mass was then incrementally reduced by a total of 150 $\mathrm{kg}$. For each mass reduction, the components were resized to maintain the acceleration, grade and battery life. Finally, the efficiency and cost were compared.

The Future Automotive Systems Technology Simulator (FASTSim) captured the efficiency and cost trade-offs of lightweighting. FASTSim is the U.S. Department of Energy's (DOE's) high-level vehicle powertrain model developed at the National Renewable Energy Laboratory. It models conventional, HEV, PHEV, and EV powertrain efficiency, battery life, and cost.

\section{Vehicle Efficiency}

FASTSim models efficiency by stepping through the U.S. Environmental Protection Agency's time versus speed drive cycles shown in Figure 2 and Figure 3 . At each step, it calculates the road loads, including drag, acceleration, ascent, and rolling resistance. The component power to achieve these loads is estimated along with their corresponding efficiency losses. These include the engine, motor, transmission, and battery. Additional key aspects captured include regenerative braking, an energy management strategy, and auxiliary loads.

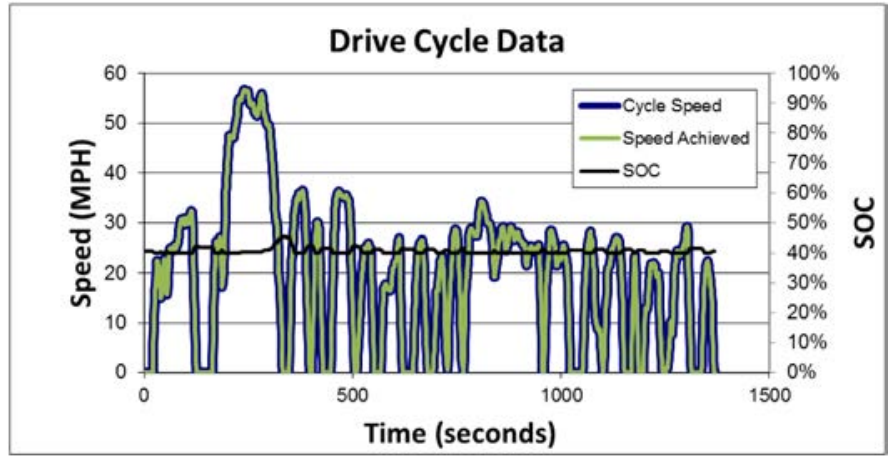

Figure 2. Urban Dynamometer Driving Schedule

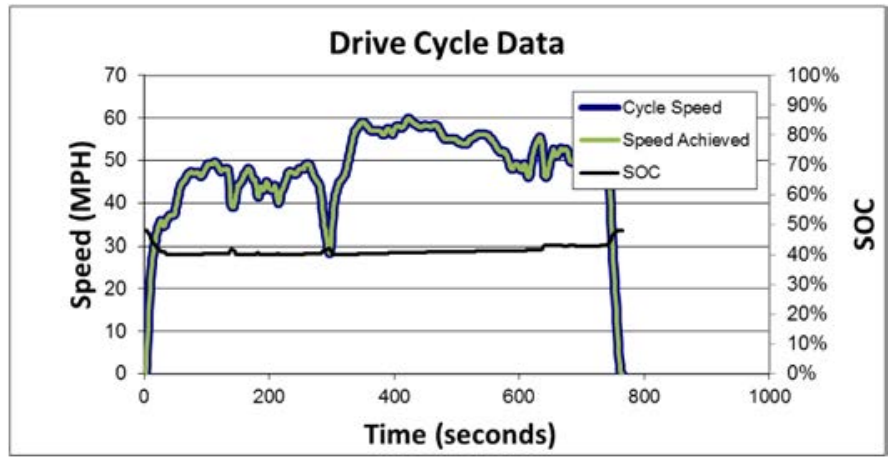

Figure 3. Highway Fuel Economy driving schedule

The simulated drive cycle efficiencies are adjusted to approximate real-world driving using the U.S. Environmental Agency's two cycle approximation of the five cycle procedure [3]. For the PHEV, the city and highway cycles were repeated until the battery stopped having a net discharge and one full charge sustaining cycle was completed. The adjustment equations were applied to each repetition. The repetitions were combined by using a weighted average based on the amount of travel at each distance interval, as described by [4]. As seen in Figure 4 and Figure 5, the model efficiency estimates match well with actual data for a variety of vehicles.

\section{Fuel Economy Validation}

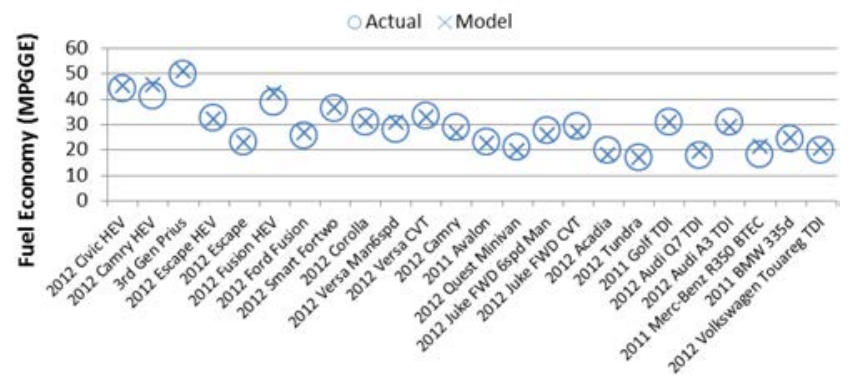

Figure 4. FASTSim fuel economy validation 


\section{Electricity Consumption Validation}

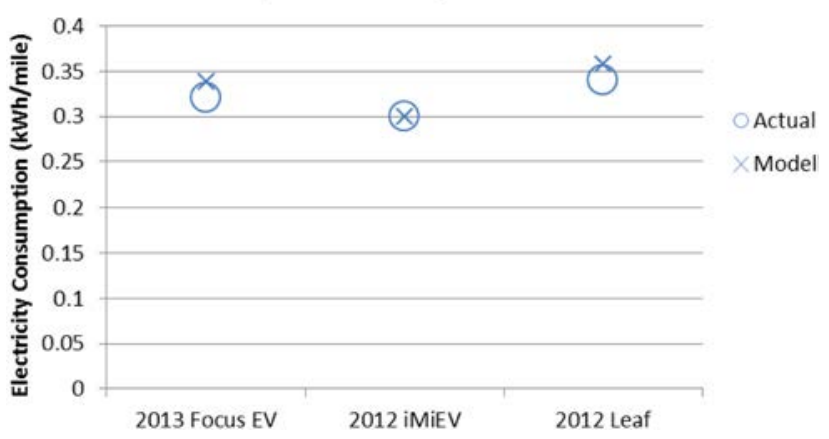

Figure 5. FASTSim EV efficiency validation

\section{Battery Life}

Vehicle efficiency impacts battery cycling and life. FASTSim estimates battery life based on the number of cycles at their corresponding depth of discharge, as described in [్], using test data from Johnson Controls [6]. It captures the small battery cycles from regenerative braking and acceleration and the deeper cycles of PHEVs and EVs from recharging the battery. The deeper cycles are based on the vehicle efficiency and the distribution of distances driven [4], as seen in Figure 6. Similar to FASTSim's efficiency, its battery life estimates match well with the data, as seen in Figure 7.

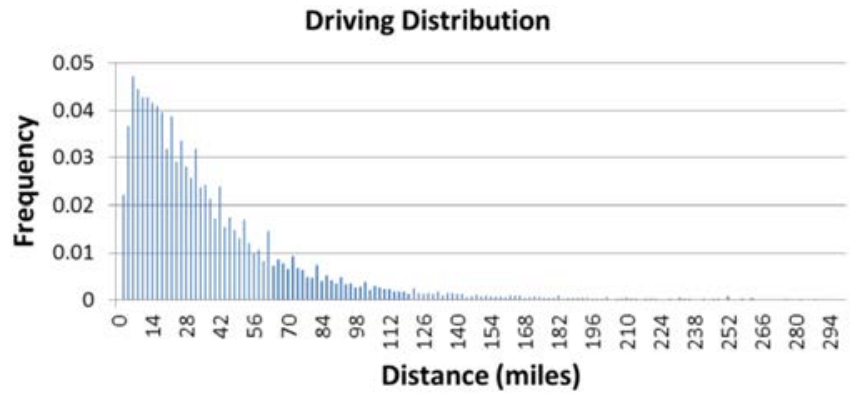

Figure 6. Distribution of driving distances

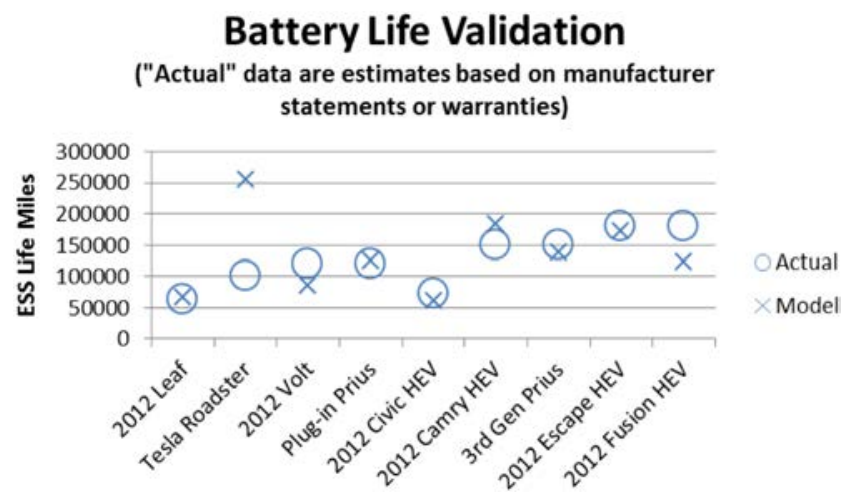

Figure 7. Battery life model validation

Future improvements in battery life were not included.

\section{Vehicle Cost}

FASTSim captures the cost of the vehicles using high-level component-based equations as seen in Table 1. The component costs are converted to price by multiplying by the component markup. The equations were applied to existing vehicles and found to match actual vehicle prices well as seen in Figure 8 .

Table 1. FASTSim Cost Model Equations

\begin{tabular}{|l|l|}
\hline Battery [7] $^{a}$ & $\$ 22 / \mathrm{kW}+\$ 500 / \mathrm{kWh}+\$ 680$ \\
\hline Motor/controller [7] & $\$ 21.7 / \mathrm{kW}+\$ 425$ \\
\hline Engine [7] & $\$ 14.5 / \mathrm{kW}+\$ 531$ \\
\hline Onboard charger [8] & $\$ 500$ \\
\hline Component markup [9] & 1.5 \\
\hline \multicolumn{2}{|c|}{$\begin{array}{l}\text { The battery energy cost was updated to \$500/kWh to match the cost of } \\
\text { existing vehicles. Although battery costs may go down in the future, } \\
\text { making replacement costs lower, this analysis assumes a constant price. }\end{array}$}
\end{tabular}

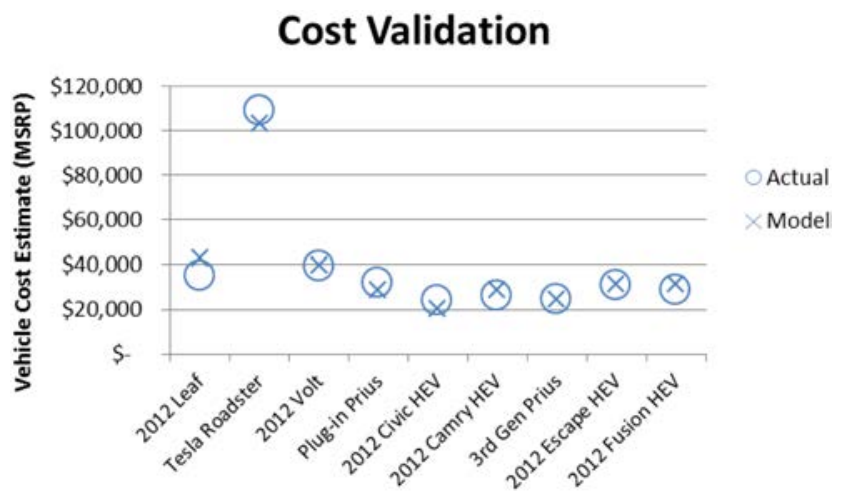

Figure 8. FASTSim cost validation

The cost of lightweighting was varied between $\$ 0 / \mathrm{kg}$ and $\$ 12 / \mathrm{kg}$ based on [10].

\section{Lightweighting}

Lightweighting impacts vehicles in multiple dimensions. It provides an opportunity to reduce the component powers and still maintain the same performance. For PHEVs and EVs, it reduces the battery energy, and thus cost, to achieve the same electric range. FASTSim optimizes component sizes at different weights to make comparisons of different levels of lightweighting across different powertrains.

The process starts by selecting a base vehicle. The base vehicle establishes the common vehicle characteristics including drag, rolling resistance, and baseline acceleration. Next, the powertrain's specific characteristics are defined, including the motor power, electric range, and battery life coefficients. Finally, each powertrain is optimized for the range of vehicle masses. 
The conventional vehicle's engine power is minimized while still meeting the baseline vehicle's acceleration and grade performance over the range of vehicle masses.

HEV optimization involves two components. The battery energy is specified, but the depth of discharge is limited to meet the life target. The engine is sized to meet the performance target.

Similarly, the PHEV has two components optimized at each vehicle weight. The battery's energy and depth of discharge are optimized to meet the specified electric range and life. The engine power is optimized to maintain acceleration and grade performance.

The EV has one significant change to the optimization process. Whereas the other vehicles optimize the engine power to meet acceleration, the EV must use the battery. Therefore, the EV's battery power, energy, and depth of discharge are optimized to meet the acceleration, electric range, and life specified.

Applying this approach to examine lightweighting requires accurately modeling three key aspects:

- Component mass scaling

- Mass compounding

- Mass impacts on efficiency

Mass data were gathered on the scaled components. Eight Toyota and Ford engines were used to define the engine mass scaling, as seen in Figure 9. The $0.47 \mathrm{x}$ mass scaling coefficient was increased $50 \%$ to account for engine-related components. The increase is supported by the compounding mass validation seen in Figure 11.

\section{Engine Mass Scaling}

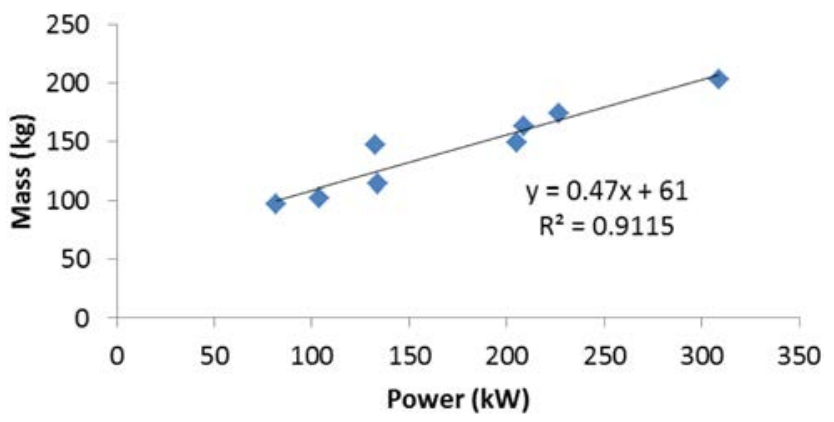

Figure 9. Engine mass scaling data

Similarly, data on nine batteries were used to define the battery scaling, as seen in Figure 10. Again, the $8.5 \mathrm{x}$ trend line coefficient was increased $50 \%$ to account for additional battery-related mass such as packaging and thermal management hardware. The increase is also supported by the compounding mass validation seen in Figure 11.

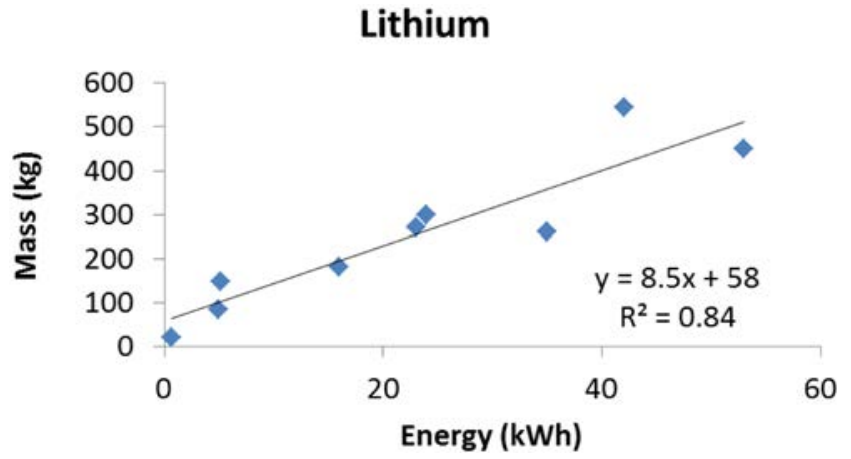

Figure 10. Battery mass scaling

Component mass has compounding vehicle-level mass impacts. As component masses are increased, other components need to be resized to support that mass. Conversely, component mass reductions lead to additional vehicle mass reductions. To account for this, a 0.4 mass compounding factor was applied based on [11].

The mass scaling and compounding was verified by comparing conventional vehicle masses to their advanced counterparts, as seen in Figure 11. The processes started with a conventional vehicle's engine size and mass. The powertrain was then modified to match the hybrid or electric version of the same vehicle using the component scaling and mass compounding previously described. Finally, the modified modeled mass was compared with the actual advanced vehicle mass.

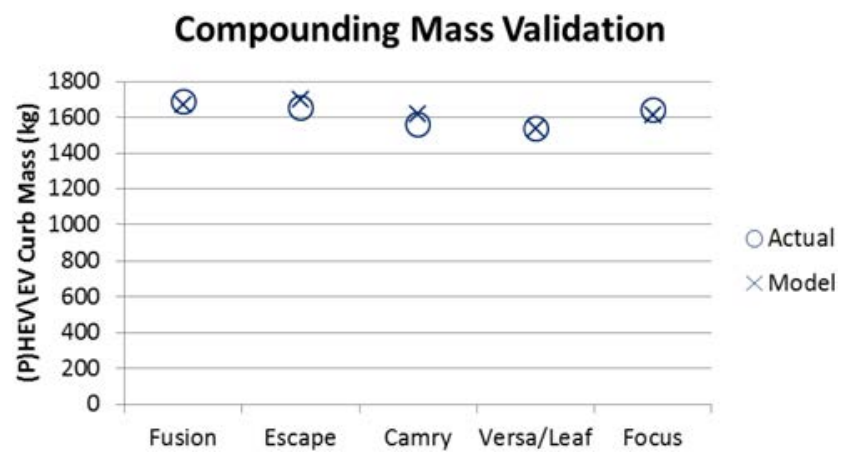

Figure 11. Mass compounding validation

After ensuring that the mass scaling and compounding were valid, FASTSim was tested to ensure that it captured the impact of mass on efficiency accurately. The Idaho National Laboratory tested the Nissan Leaf at several different weights by adding mass to the vehicle [12]. For each weight, coast down tests were run to capture impacts on the drag forces. Then the vehicle was tested on a chassis dynamometer to estimate the impact on efficiency. This process was duplicated in FASTSim and compared to the data reported by Idaho National Laboratory, which matched well, as seen in Figure 12. 


\section{EV Mass Impact on Efficiency Validation}

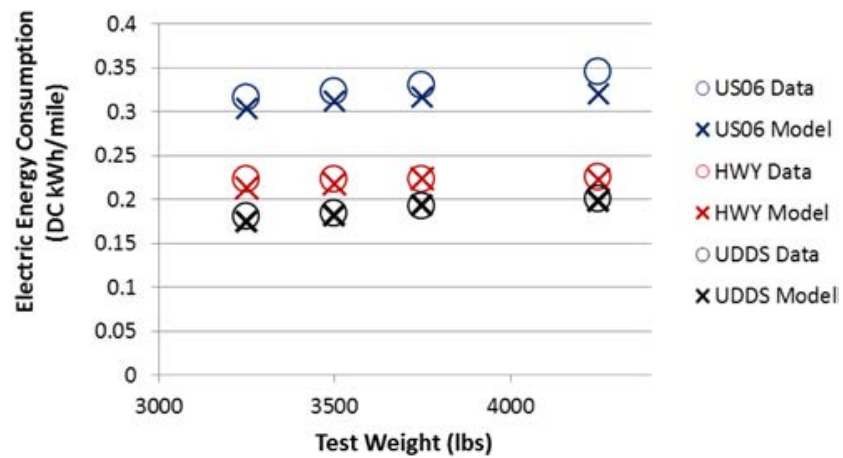

Figure 12. Mass impact on efficiency validation

As a final check for modeling lightweighting, two test cases were run and compared with another study. First, a $10 \%$ reduction in the conventional vehicle mass was run without engine resizing. The $4 \%$ reduction in fuel economy matched closely to the $4.1 \%$ in [13]. Similarly, a $10 \%$ reduction in the conventional vehicle mass was run with engine resizing. Again, the $6.3 \%$ fuel economy improvement matched closely to the $6.4 \%$ found in [13] .

\section{ASSUMPTIONS}

After setting up and validating the approach, the analysis assumptions were made, as seen in Table 2.

Table 2. Analysis Assumptions

\begin{tabular}{|l|l|}
\hline $\begin{array}{l}\text { Average annual vehicle miles } \\
\text { traveled (VMT) [14] }\end{array}$ & 12,375 \\
\hline $\begin{array}{l}\text { Average annual VMT decline } \\
\text { [15] }\end{array}$ & 546 \\
\hline Vehicle life (years) [16] & 15 \\
\hline Gasoline price (\$/gallon) & $\$ 4.00$ \\
\hline Electricity price (\$/kWh) [17] & $\$ 0.10$ \\
\hline Discount rate [18] & $4.1 \%$ \\
\hline $\begin{array}{l}\text { Glider price (vehicle without } \\
\text { powertrain) }\end{array}$ & $\$ 17,014$ \\
\hline Battery cost [7] & $\$ 500 / \mathrm{kWh}+\$ 22.2 / \mathrm{kW}+\$ 680$ \\
\hline Motor/controller cost [7] & $\$ 21.7 / \mathrm{kW}+\$ 425$ \\
\hline Engine cost [7] & $\$ 14.5 / \mathrm{kW}+\$ 531$ \\
\hline
\end{tabular}

Table 2 (cont).

\begin{tabular}{|l|l|}
\hline Onboard charger [8] & $\$ 500$ \\
\hline Component markup [9] & 1.5 \\
\hline Tax [19] & $7.8 \%$ \\
\hline Baseline vehicle & Nissan Leaf \\
\hline Baseline curb mass (kg) [20] & 1,701 \\
\hline Drag coefficient [20] & 0.32 \\
\hline Frontal area (m²) [20] & 2.74 \\
\hline $\begin{array}{l}\text { Rolling resistance coefficient } \\
\text { [20] }\end{array}$ & 0.009 \\
\hline Drive cycle & $\begin{array}{l}\text { U.S. Environmental } \\
\text { city/highway }\end{array}$ \\
\hline $\begin{array}{l}\text { Auxiliary load (W) [21] } \\
\text { (miles) }\end{array}$ & 280 \\
\hline $\begin{array}{l}\text { Acceleration time (seconds 0- } \\
60 \text { MPH) }\end{array}$ & 9.5 \\
\hline $\begin{array}{l}\text { Max speed at 6\% grade using } \\
\text { 2/3 } \text { rongine power (MPH) }\end{array}$ & 60 \\
\hline HEV motor power (kW) [22] & 30 \\
\hline PHEV battery energy (kWh) & 1.3 \\
\hline EV battery replacements [24] & 2 \\
\hline
\end{tabular}

\section{RESULTS}

Lightweighting the glider mass had compounding effects that led to greater total vehicle mass reductions as seen in Figure $\underline{13}$. 
Total Mass

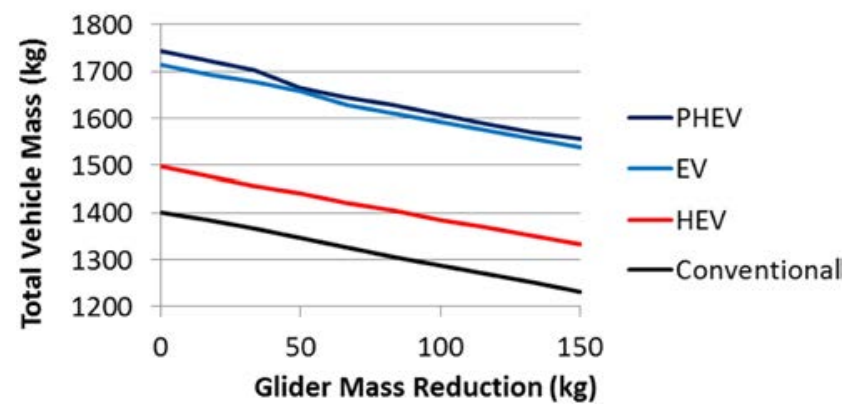

Figure 13. Glider lightweighting impact on total vehicle mass

Lightweighting improved efficiency in several dimensions. It primarily reduced the braking and rolling resistance losses, with some improvement to engine operating efficiency. The braking and rolling resistance losses are shown in Figure 14. The engine efficiency improved less than $1 \%$.

\section{Lightweighting Energy Loss Reduction}

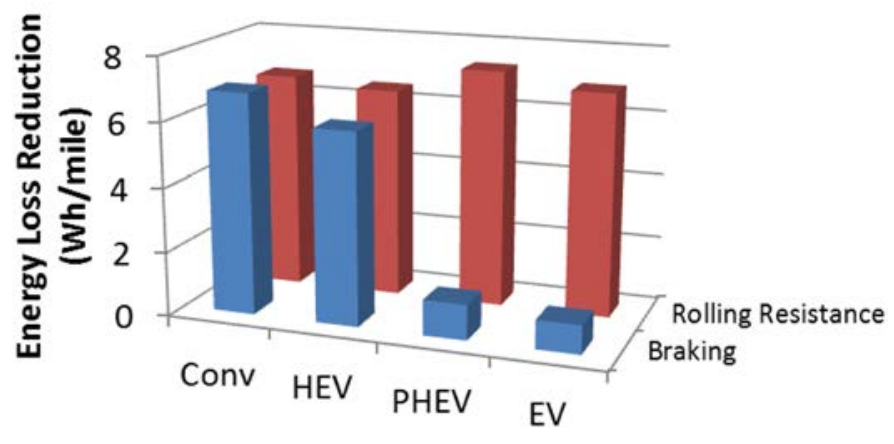

Figure 14. Road load energy loss improvement from 150 kg glider mass reduction

Although the rolling resistance and braking energy reductions are modest, they reduce fuel use much more because the engine requires roughly three to four times the fuel energy to support those loads due to the engine's efficiency losses, as seen in Figure 15. This is most pronounced for the conventional vehicle. Because the hybrid engine uses the more efficient Atkinson cycle, the multiplier effect is smaller. Similarly, an electric motor has much greater efficiency than a gasoline engine, so the PHEV and EV road load reductions are amplified much less.

\section{Lightweighting Energy Loss Reduction}

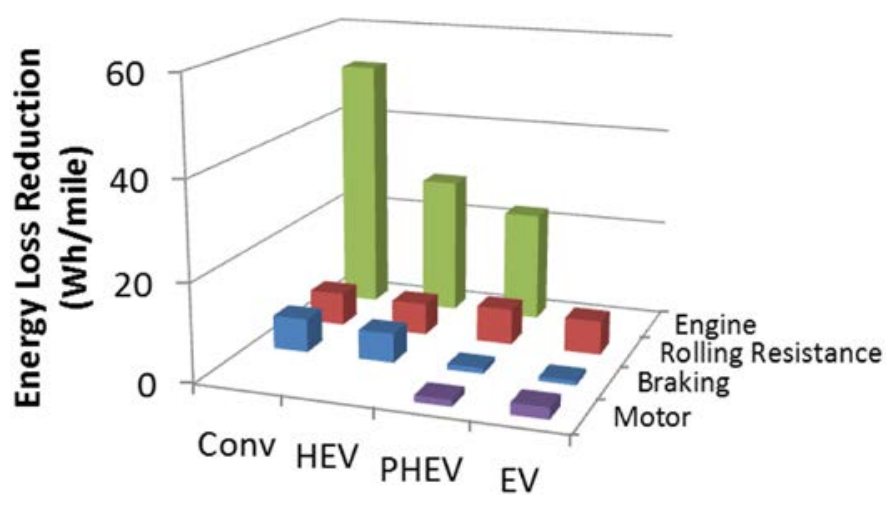

Figure 15. Energy loss improvement from $150 \mathrm{~kg}$ glider mass reduction

Overall, the conventional vehicle had the greatest efficiency benefit from lightweighting. Without regenerative braking, it had the greatest amount of braking losses, and thus achieved the greatest reduction in those losses. Similarly, because more fuel goes through its engine and its engine is less efficient, it benefited most from the engine operating efficiency improvement from engine downsizing. The fuel consumption decreased from $8.13 \mathrm{~L} / 100 \mathrm{~km}$ to $7.55 \mathrm{~L} / 100 \mathrm{~km}$, a difference of $0.58 \mathrm{~L} / 100 \mathrm{~km}$, from eliminating $150 \mathrm{~kg}$ of mass.

Lightweighting the HEV provided almost as much benefit as it did for the conventional vehicle. It benefited from similar rolling resistance improvements and almost as much braking improvement.

The braking improvement was due to the control strategy settings in FASTSim. The HEV has regenerative braking, which provides the majority of braking, but not all. Primarily, the control strategy is set for the battery to provide power when the engine needs assistance. At a high state of charge and speed, some additional battery power is used to assist the engine and provide capacity for the next braking regeneration event. The priority to use the battery to reduce the state of charge, however, is not sufficient to always capture all the regenerative braking energy. This priority has been optimized to balance the present fuel cost and battery wear cost. Increasing the priority to capture more regenerative braking increases battery wear cost more than it reduces fuel cost. For example, a higher battery assist level decreased fuel consumption from $5.35 \mathrm{~L} / 100 \mathrm{~km}$ to $5.23 \mathrm{~L} / 100 \mathrm{~km}$, but it increased wear by $18 \%$ and present vehicle and fuel cost by $5 \%$. Likewise, decreasing the battery use was not worth the fuel consumption increase.

The HEV did not benefit from lightweighting as much as the conventional vehicle. The HEV's fuel consumption decreased from $5.35 \mathrm{~L} / 100 \mathrm{~km}$ to $5.00 \mathrm{~L} / 100 \mathrm{~km}$, a difference of 0.35 $\mathrm{L} / 100 \mathrm{~km}$ from eliminating $150 \mathrm{~kg}$ of mass. 
The PHEV and EV efficiencies also improved from lightweighting. Their rolling resistance reduction was slightly greater because they were heavier than the conventional vehicle and the HEV. Their other loss improvements, however, were much lower. The PHEV improved from an overall average $2.95 \mathrm{~L} / 100 \mathrm{~km}$ and $167 \mathrm{Wh} /$ mile to 2.79 $\mathrm{L} / 100 \mathrm{~km}$ and $157 \mathrm{Wh} / \mathrm{mile}$ from eliminating $150 \mathrm{~kg}$ of mass, a difference of $0.16 \mathrm{~L} / 100 \mathrm{~km}$ of gasoline. The EV improved from $347 \mathrm{Wh} /$ mile to $329 \mathrm{Wh} / \mathrm{mile}$.

Although the conventional vehicle realized the largest gasoline consumption improvement, it still uses far more gasoline than the other powertrains, as seen in Figure 16.

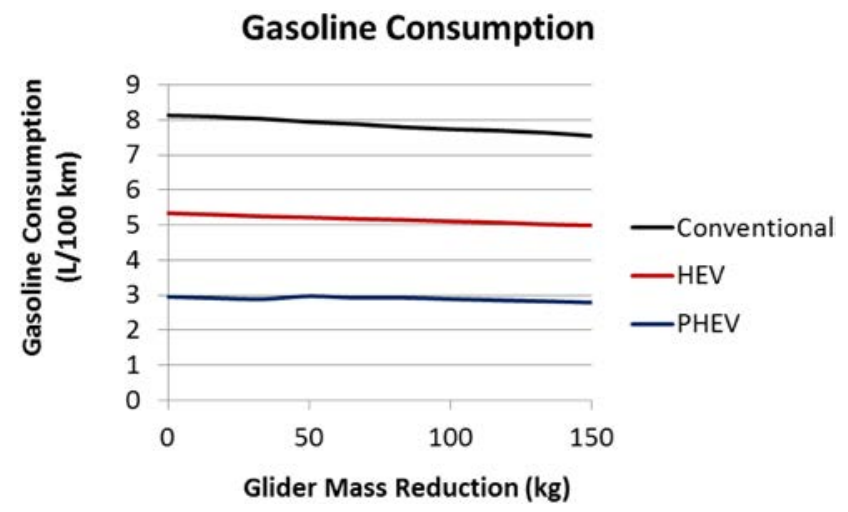

Figure 16. Lightweighting impact on gasoline consumption

Electricity consumption also dropped with lightweighting, as seen in Figure 17.

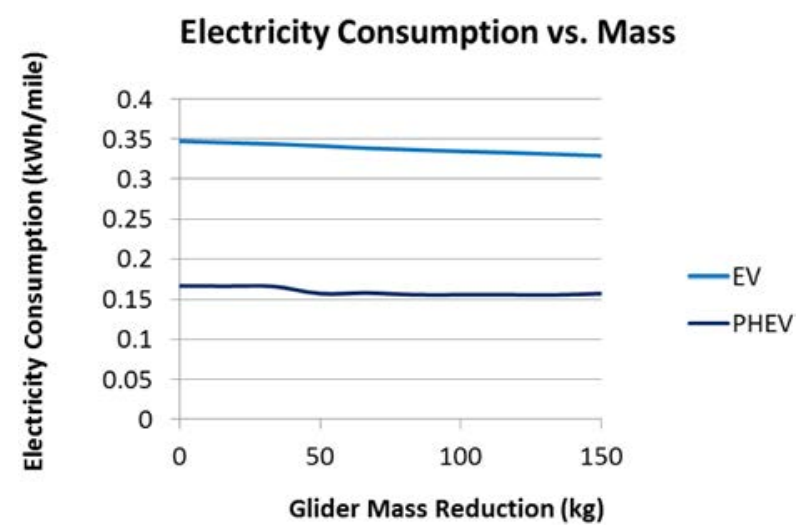

Figure 17. Lightweighting impact on electricity consumption

The energy consumption benefits translate into fuel cost benefits, as seen in Figure 18. These are the vehicle lifetime fuel costs discounted at $4.1 \%$. The greatest impact is on the conventional vehicle.

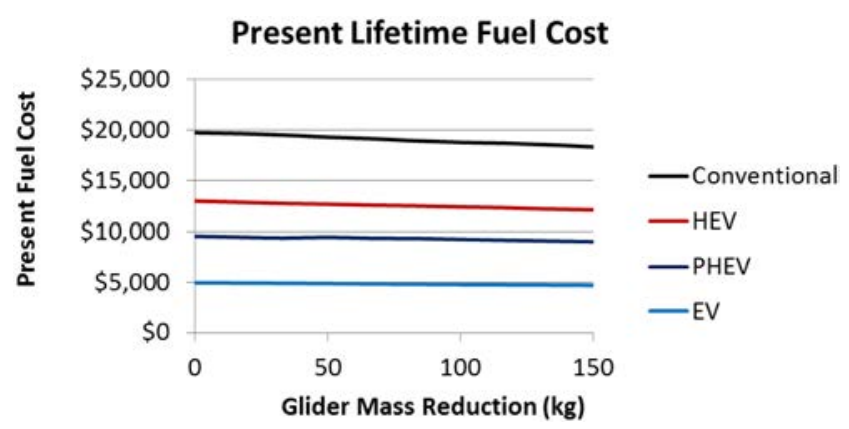

Figure 18. Lightweighting impact on fuel cost

Lightweighting not only reduced energy consumption but also powertrain component sizes, and thus, cost. The engine sizes required to meet the performance criteria can be seen in Figure 19. The conventional vehicle's engine power is significantly higher than the HEV's and EV's despite the lower total vehicle mass because it is not assisted with electric motor power. The slight variations in the trends are caused by the optimization convergence tolerances.

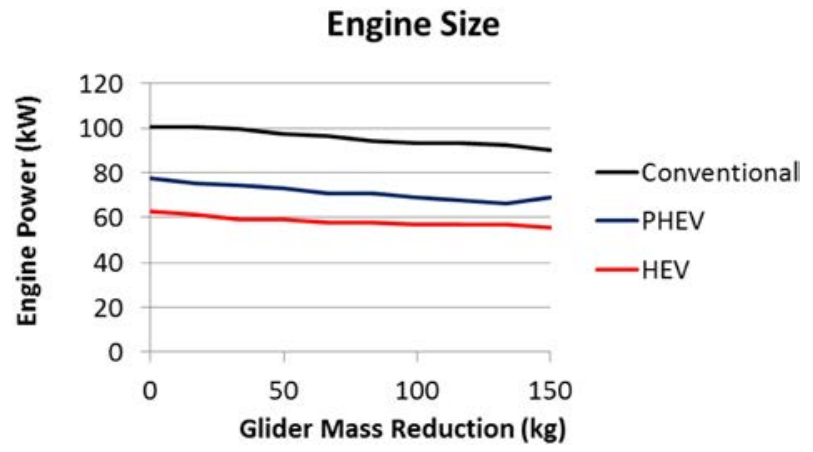

Figure 19. Engine power required to meet performance criteria

Similar to engine downsizing, the battery energy required to maintain the specified electric range decreased. The PHEV battery energy dropped from $13.4 \mathrm{kWh}$ to $12.4 \mathrm{kWh}$ over the $150 \mathrm{~kg}$ mass reduction. The EV dropped from $24 \mathrm{kWh}$ to 23 $\mathrm{kWh}$.

Component size reductions reduced vehicle price, but the cost of lightweighting increases it. As seen in Figure 20, at $\$ 6 / \mathrm{kg}$ and $\$ 12 / \mathrm{kg}$, the cost of light weighting is equal to or greater than the component cost reductions. 


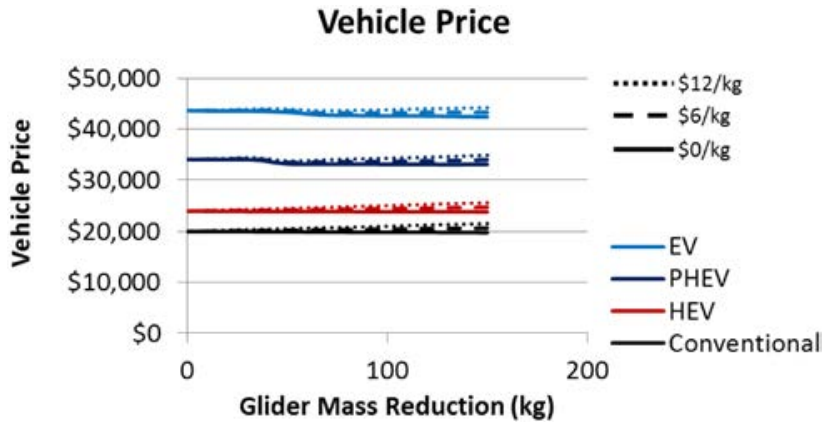

Figure 20. Lightweighting impacts on vehicle price

Although the Nissan Leaf is priced at $\$ 35,200$ [25], the EV in this study started at about $\$ 43,500$. The additional price is estimated based on an increase in battery and motor power to achieve a 9.5 second 0-60 mile per hour (MPH) acceleration that is more typical of vehicles today, compared to the 10.3second acceleration of the Nissan Leaf [ㄹ] $]$.

The battery resizing decreased the cost of future battery replacement for the PHEV and EV, as seen in Figure 21.

\section{Present Battery Replacement Cost}

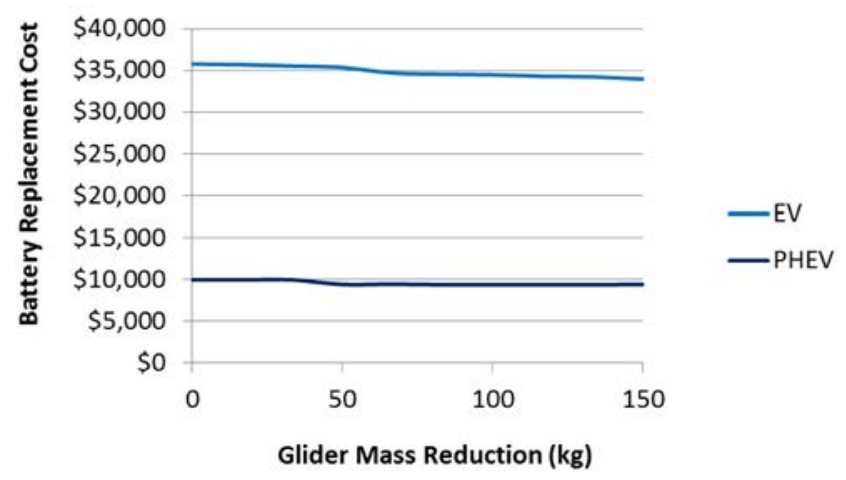

Figure 21. Lightweighting impact on battery replacement cost

The fuel, component resizing, and battery replacement cost improvements are summarized in Figure 22.

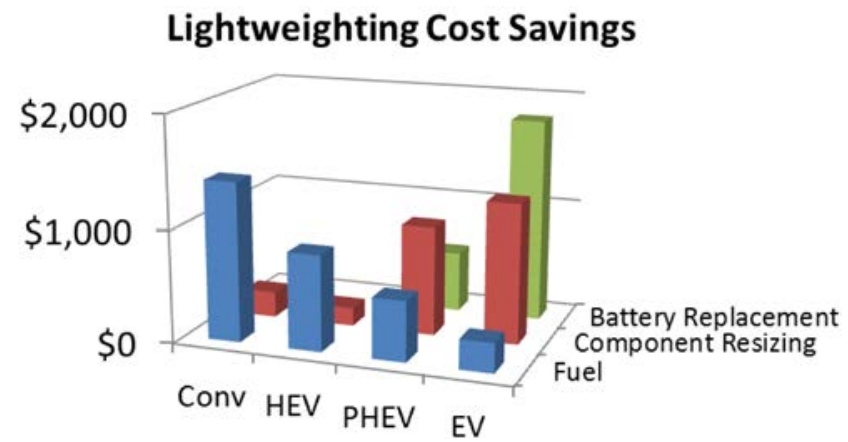

Figure 22. Lightweighting cost savings from $150 \mathrm{~kg}$ glider mass reduction
Although the cost improvements for the EV and PHEV are the greatest, those powertrains still cost more than the conventional vehicle and HEV, as seen in Figure 23.

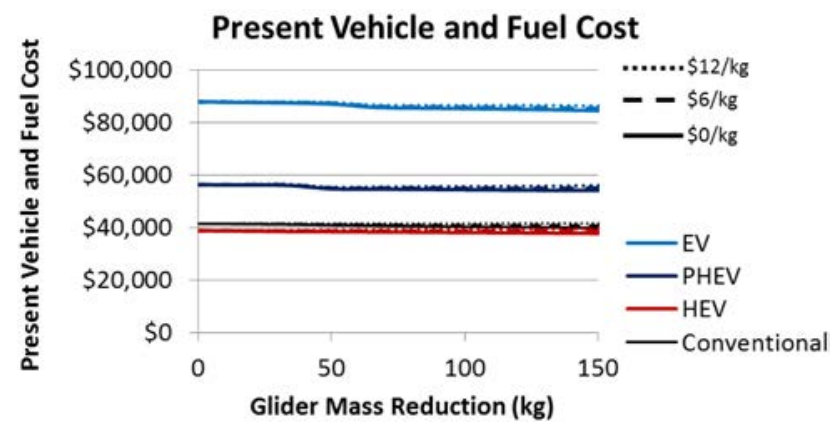

Figure 23. Lightweighting impacts on total cost

Because the conventional vehicle and HEV are more costeffective at the assumed battery cost levels, Figure 24 zooms in on them. This shows that when including fuel cost, component downsizing, and battery replacement reductions, lightweighting becomes cost effective around \$6 per kilogram [10] of mass eliminated.

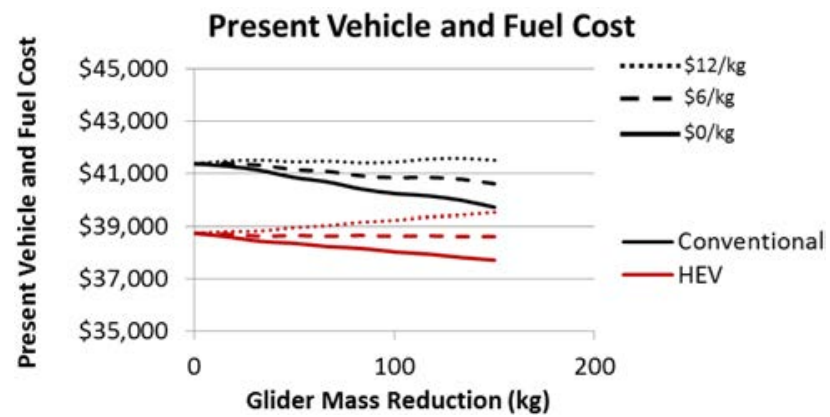

Figure 24. Lightweighting impact on total cost

If the DOE's EV battery cost target of $\$ 125 / \mathrm{kWh}$ [27] is met and the batteries last the life of the vehicle, the PHEV and EV also become cost effective. Then, similarly, lightweighting for the PHEV and EV is cost effective around $\$ 6$ per kilogram of mass eliminated, as seen in Figure 25.

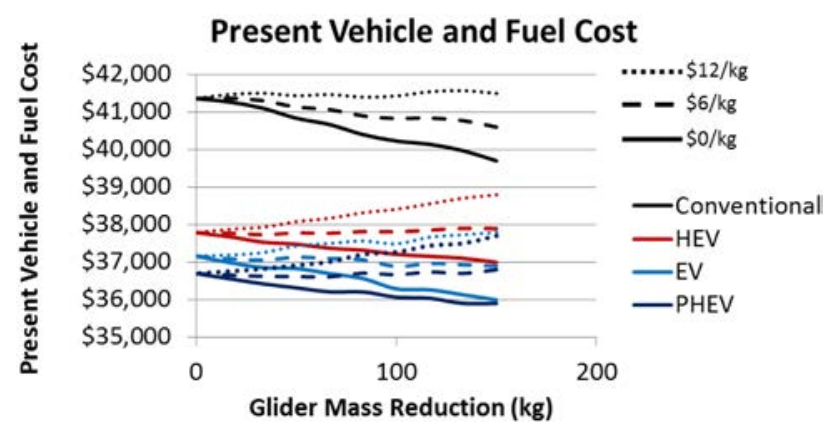

Figure 25. Lightweighting impact on total cost when meeting DOE's EV battery target of $\$ 125 / \mathrm{kWh}$ 


\section{SUMMARY/CONCLUSIONS}

For the specified assumptions, lightweighting impacted the four powertrains differently but had similar end outcomes. The conventional vehicle had the largest fuel consumption, and thus, fuel cost benefit. Lightweighting reduced its rolling resistance roughly the same amount as the other powertrains, but improved the braking and engine losses more. Although the conventional vehicle benefited most from the fuel cost reductions, the PHEV and EV benefited most from battery cost reductions from downsizing. Overall, the cost reductions for the PHEV and EV were greatest, but the conventional vehicle and HEV powertrains were still lower cost. When the DOE's battery target of $\$ 125 / \mathrm{kWh}$ is met, the PHEV and EV lightweighting benefit diminishes compared to the conventional vehicle, but it becomes lower cost.

Although lightweighting decreases component and fuel cost, it increases the vehicle glider cost. Lightweighting that costs less than $\$ 6 / \mathrm{kg}$ of mass eliminated was cost effective.

\section{REFERENCES}

1. U.S. Energy Information Administration, "Annual Energy Review," Table 2.1e, September 2012, http://www.eia.gov/ totalenergy/data/annual/showtext.cfm?t=ptb0201e, retrieved October 25, 2012.

2. U.S. Energy Information Administration, "Energy in Brief: How dependent are we on foreign oil?" http:// www.eia.gov/cfapps/energy_in_brief/ foreign_oil_dependence.cfm? featureclicked $=3$, retrieved October 22, 2012.

3. Labeling of Motor Vehicles: Revisions to Improve Calculation of Fuel Economy Estimates; Final Rule, Code of Federal Regulations, Title 40, Parts 86 and 600, December 27, 2006, http://www.epa.gov/fedrgstr/EPA-AIR/2006/ December/Day-27/a9749.pdf.

4. Hu, P., and Reuscher, T., "2001 National Household Travel Survey, Summary of Travel Trends," U.S. Department of Transportation Federal Highway Administration, December 2004.

5. Brooker, A., Thornton, M., and Rugh, J., "Technology Improvement Pathways to Cost-Effective Vehicle Electrification," SAE Technical Paper 2010-01-0824, 2010: doi: 10.4271/2010-01-0824.

6. Duvall, M., "Batteries for Plug-In Hybrid Electric Vehicles," presented at The Seattle Electric Vehicle to Grid (V2G) Forum, June 6, 2005.

7. Simpson, A., "Cost Benefit Analysis of Plug-In Hybrid Electric Vehicle Technology," presented at the $22^{\text {nd }}$ International Battery, Hybrid and Fuel Cell Electric Vehicle Symposium and Exhibition, Yokohama, Japan, Oct. 2006, NREL/CP-540-40485, November 2006, www.nrel.gov/ vehiclesandfuels/vsa/pdfs/40485.pdf.
8. Yilmaz, M., Krein, P., "Review of Charging Power Levels and Infrastructure for Plug-in Electric and Hybrid Vehicles and Commentary on Unidirectional Charging," presented at the IEEE International Electrical Vehicle Conference, March 2012.

9. Rogozhin, A., Gallaher, M., Helfand, G., McManus, W., "Using indirect cost multipliers to estimate the total cost of adding new technology in the automobile industry," International Journal of Production Economics, Volume 124, Issue 2, April 2010, Pages 360-368.

10. Fine, C., and Roth, R., "Lightweight Materials for Transport: Developing a Vehicle Technology Roadmap for the Use of Lightweight Materials," presented at the MIT Roundtable: The Future of Manufacturing Innovation Advanced Technologies http://www.alum.mit.edu/sites/ default/files/IC_assets/news/images/alumninews/ Fine_Roth.pdf, March 29, 2010.

11. Malen, D. E., Reddy, K., "Preliminary Vehicle Mass Estimation Using Empirical Subsystem Influence Coefficients," June 2007, http://www.steel.org/ /media/ Files/Autosteel/Research/Lightweighting/ mass compoundingpdf.pdf, retrieved October 29, 2012.

12. Francfort, J., Carlson, R., "Vehicle Mass Impact on Vehicle Losses and Fuel Economy," presented at the 2012 DOE Vehicle Technologies Program Annual Merit Review, May 2012.

13. Casadei, A., Broda, R., "Impact of Vehicle Weight Reduction on Fuel Economy for Various Vehicle Architectures," presentation prepared for The Aluminum Association, Inc., December 2007.

14. U.S. Department of Transportation Federal Highway Administration Highway Statistics 2005, "Annual Vehicle Distance Traveled in Miles and Related Data," http:// www.fhwa.dot.gov/policy/ohim/hs05/htm/vm1.htm, posted November 2006, retrieved October 14, 2009.

15. Oak Ridge National Laboratory, "Transportation Energy Data Book," Edition 29, Table 3.7, 2010.

16. Research and Innovative Technology Administration Bureau of Transportation Statistics, "Table 1-11, Number of U.S. Aircraft, Vehicles, Vessels, and Other Conveyances," http://www.bts.gov/publications/ national transportation statistics $/ 2002 / \mathrm{html} /$ table 01_11.html, retrieved October 14, 2009.

17. U.S. Energy Information Administration (EIA), "Electric Power Monthly: Table 5.3 - Average Retail Price of Electricity to Ultimate Customers," http://www.eia.gov/ electricity/monthly/epm table_grapher.cfm?t=epmt 5 03, release date September 24, 2012, retrieved October 29, 2012.

18. Easterling, E., "In Investing, It's When You Start and When You Finish," The New York Times, http:// www.nytimes.com/interactive/2011/01/02/business/ 20110102-metrics-graphic.html, retrieved October 29, 2012. 
19. Consumer Reports, "High Cost of Hybrid Vehicles, Ownership Cost Comparison," http:// www.consumerreports.org, retrieved October 14, 2009.

20. U.S. Environmental Protection Agency, "Test Car List Data Files," http://www.epa.gov/otaq/cert/mpg/testcars/ database/12tstcar-2012-03-05.csv, retrieved October 29, 2012.

21. Lohse-Busch, H., Duoba, M., and Rask, E., "Advanced Powertrain Research Facility AVTA Nissan Leaf Testing and Analysis," presented at the 2012 DOE Hydrogen Program and Vehicle Technologies Annual Merit Review, May 2012.

22. U.S. Department of Energy, Office of Energy Efficiency and Renewable Energy, "2010 Toyota Prius-0462 Hybrid BOT Battery Test Results," http://www1.eere.energy.gov/ vehiclesandfuels/avta/pdfs/hev/batterygenIIIprius0462.pdf, retrieved October 29, 2012.

23. U.S. Department of Energy, U.S. Environmental Protection Agency, "Nissan Leaf miles on a charge," www.fueleconomy.gov, retrieved October 29, 2012.

24. Nissan USA Q\&A, "For general automotive purposes, Nissan sees a 5-year battery life," www.nissanusa.com/leafelectric-car, posted February 01, 2010.

25. Nissan USA, “2012 Nissan Leaf SV," http:// www.nissanusa.com/leaf-electric-car/versions-specifications? next $=$ ev micro.section nav, retrieved November 5, 2011.

26. Consumer Reports, "Cars - Car ratings," http:// www.consumerreports.org/cro/cars/index.htm, retrieved November 1, 2012.

27. Howell, D., "Battery Status and Cost Reduction Prospects," presented at the EV Everywhere Grand Challenge Battery Workshop, July 2012, http://www1.eere.energy.gov/ vehiclesandfuels/pdfs/ev everywhere $/ 5$ howell b.pdf.

\section{CONTACT INFORMATION}

Aaron Brooker, Senior Research Engineer National Renewable Energy Laboratory (NREL)

Tel: 303-275-4392

Aaron.Brooker@nrel.gov

\section{ACKNOWLEDGMENTS}

The authors gratefully acknowledge the support for this work provided by Jacob Ward and Patrick Davis in the Vehicle Technologies Program of the U.S. Department of Energy's Office of Energy Efficiency and Renewable Energy.

\section{DEFINITIONS/ABBREVIATIONS}

DOE - Department of Energy

EV - Battery electric vehicle

FASTSim - Future Automotive Systems Technology Simulator

HEV - Hybrid electric vehicle

PHEV - Plug-in hybrid electric vehicle

SOC - State of charge
The Engineering Meetings Board has approved this paper for publication. It has successfully completed SAE's peer review process under the supervision of the session organizer. This process requires a minimum of three (3) reviews by industry experts. ISSN 0148-7191
Positions and opinions advanced in this paper are those of the author(s) and not necessarily those of SAE. The author is solely responsible for the content of the paper.

SAE Customer Service:

Tel: 877-606-7323 (inside USA and Canada)

Tel: 724-776-4970 (outside USA)

Fax: 724-776-0790

Email: CustomerService@sae.org

SAE Web Address: http://www.sae.org

Printed in USA 